International Journal of Applied Dental Sciences 2022; 8(1): 15-19

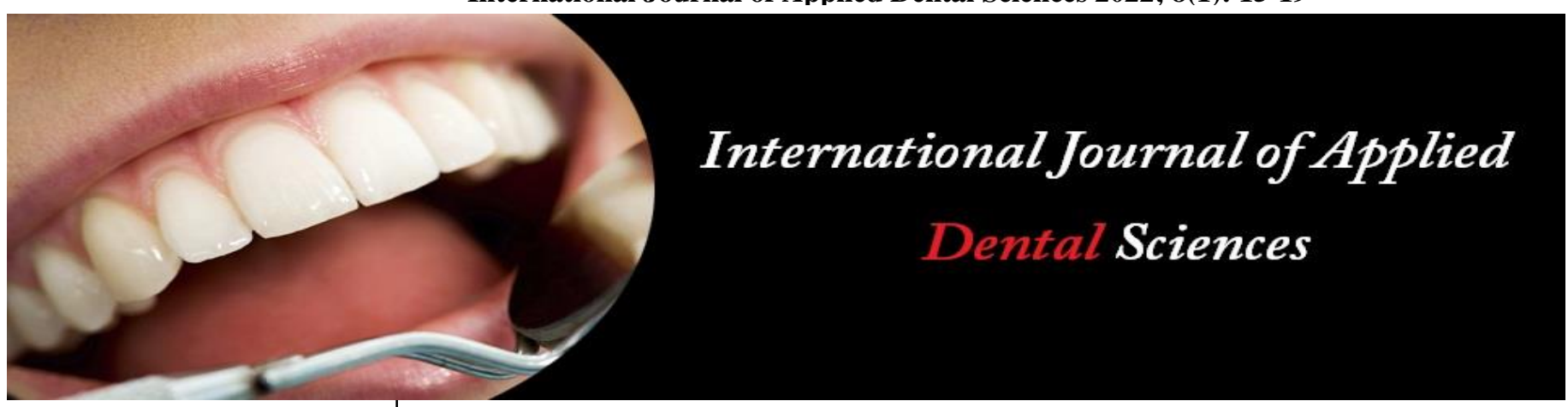

ISSN Print: 2394-7489

ISSN Online: 2394-7497

IJADS 2022; 8(1): 15-19

(C) 2022 IJADS

www.oraljournal.com

Received: 24-10-2021

Accepted: 10-12-2021

Dr. Ravisha S Salve

Junior Resident, Department of

Orthodontic and Dentofacial

Orthopedics, CSMSS Dental

College and Hospital,

Aurangabad, Maharashtra, India

Dr. Jeevan M Khatri

HOD and Professor, Department of Orthodontics and Dentofacial Orthopaedics, CSMSS Dental

College and Hospital,

Aurangabad, Maharashtra, India
Corresponding Author:

Dr. Ravisha S Salve

Junior Resident, Department of

Orthodontic and Dentofacia

Orthopedics, CSMSS Dental

College and Hospital,

Aurangabad, Maharashtra, India

\section{Allergies and its management in orthodontics}

\author{
Dr. Ravisha S Salve and Dr. Jeevan M Khatri
}

DOI: $\underline{\text { https://doi.org/10.22271/oral.2022.v8.i1a.1397 }}$

\section{Abstract}

Allergic reactions are of increasing concern to practitioners in health-related fields. In modern orthodontic practice, adverse patient reactions to orthodontic materials are of both an irritant and a allergic in nature. Allergy in patients undergoing orthodontic treatment can be seen due to several reasons and these include nickel allergy, allergy to the acrylic resins that are used during treatment, latex products, etc. Safe and effective practice depends on identifying patients with allergy along with knowledge of materials that can potentially cause them. The Orthodontists should have basic understanding of allergic reactions and should be efficient enough to manage them. The aim of this paper is to review and analyse critically the current available literature in the field of allergy in orthodontics and to provide clinical implications based on scientific evidence on the topic.

Keywords: allergy, orthodontics, management

\section{Introduction}

Allergic reactions are of increasing concern to practitioners in health-related fields. In modern orthodontic practice, adverse patient reactions to orthodontic materials are of both an irritant and a allergic in nature. An allergic response is one in which certain components of the immune system react excessively to a foreign substance. Two key allergic reactions have been described in the literature. Type I hypersensitivity reactions are an immediate antibody mediated allergic response, occurring within minutes or hours after direct skin or mucosal contact with the allergen ${ }^{[1]}$. This reaction ranges from contact urticaria to full-blown anaphylaxis with respiratory distress and or hypotension. A delayed hypersensitivity reaction (Type IV), delayed-type hypersensitivity reactions (Type IV allergic reactions) are allergic immune reactions manifesting primarily through $\mathrm{T}$ cells (Cellular immunity) ${ }^{[2]}$. This process has two interrelated, distinct phases. A sensitization phase occurs from the moment the allergen enters the body, is recognized and a response occurs. The elicitation phase occurs after re-exposure to the allergen to the appearance of the full clinical reaction. It presents with diffuse or patchy eczema on the contact area and may be accompanied initially by itching, redness, and vesicle formation. Both types of allergic reactions require several prolonged contacts with allergens. Allergy in patients undergoing orthodontic treatment can be seen due to several reasons and these include nickel allergy, allergy to the acrylic resins that are used during treatment, latex products, etc. ${ }^{[3]}$ There is rising concern about the biocompatibility of dental materials; this might be due to a real increase in the occurrence of allergic reactions to the materials or to an increase in awareness of adverse effects from these materials. Safe and effective practice depends on identifying patients with allergy along with knowledge of materials that can potentially cause them. The Orthodontists should have basic understanding of allergic reactions and should be efficient enough to manage them. The aim of this paper is to review and analyze critically the current available literature in the field of allergy in orthodontics and to provide clinical implications based on scientific evidence on the topic.

\section{Nickel Allergy}

Nickel alloys are widely used in the orthodontic in brackets, wires, bands and other orthodontic accessories. Nickel allergy occurs more frequently than allergy to all other metals combined ${ }^{[4]}$. It is estimated that $11 \%$ of all women and $20 \%$ of women between the ages of 16 and 35 years have a sensitivity to nickel ${ }^{[5]}$. 
Nickel-induced contact dermatitis is a type IV delayed hypersensitivity immune response occurring at least 24 hours after exposure ${ }^{[2,6]}$. It has been shown that the level of nickel in saliva and serum increases significantly after the insertion of fixed orthodontic appliances [1]. Nickel leaching from orthodontic bands, brackets, stainless steel or Ni-Ti archwires has been shown in vitro to occur within the first week and then decline thereafter ${ }^{[7]}$. It is suggested that a threshold concentration of approximately $30 \mathrm{ppm}$ of nickel may be sufficient to elicit a cytotoxic response ${ }^{[8]}$. Scientific evidence suggests that orthodontic treatment is not associated with increase of $\mathrm{Ni}$ hypersensitivity, unless patients have a history of previous exposure to Ni. People with cutaneous piercing are considered a significant risk factor for $\mathrm{Ni}$ allergy ${ }^{[9]}$. however, oral exposure to nickel through dental braces prior to ear piercing reduces the risk of developing nickel allergy ${ }^{[10]}$. Previous allergic response after wearing earrings or a metal watchstrap, appearance of allergy symptoms shortly after the initial insertion of orthodontic components containing Nickel and confined extra-oral rash adjacent to headgear studs should raise alarm to clinician concerning nickel allergy. Signs and symptoms of nickel allergy includes gingivitis, gingival hyperplasia, lip desquamation, burning sensation in the mouth, metallic taste, angular cheilitis, and periodontitis ${ }^{[11,12]}$. In chronic cases, the affected mucosa is typically in contact with the causal agent and appears erythematous or hyperkeratotic to ulcerated. ${ }^{13}$ Extraoral manifestations of nickel allergy may have an intraoral origin ${ }^{[14]}$. If a nickel allergy is still in question, a diagnosis can be confirmed by a dermatologist by conducting a cutaneous sensitivity test called a patch test (Table 1) using 5\% nickel sulphate in petroleum jelly ${ }^{[15]}$. If intra- oral signs and symptoms (Table 2) are present and a diagnosis of nickel hypersensitivity is established, the fixed or removable prosthesis should be replaced with another nickel free alloy (Table 3 and 4). The nickel titanium archwires should be removed and replaced with a stainless steel archwire which is low in nickel content or preferably a titanium molybdenum alloy (TMA) archwire, known as "TMA", which does not contain nickel ${ }^{[16]}$. Most patients who develop a reaction to $\mathrm{Ni}$-Ti archwires subsequently tolerate stainless steel without a reaction ${ }^{[17]}$. Other options include Fiber reinforced composite wires, Gold plated wires, Ion-implanted nickel-titanium archwires or Plastic/Resin-coated nickel-titanium archwires ${ }^{[16]}$. Stainless steel brackets are generally considered safe ${ }^{[18]}$. However, nickel free alternative brackets to stainless steel include Ceramic brackets produced using polycrystalline alumina, single crystal sapphire, and zirconia, Polycarbonate brackets, Titanium brackets and Gold plated brackets and plastic brackets in selected cases Fixed appliances may be substituted with plastic aligners. Extra-oral metal components, including metal studs in headgear, are of greatest concern due to greater sensitivity of skin. Plastic coated headgear studs may be a better alternative for such patients.

Table 1: Reading of patch test

\begin{tabular}{|c|c|c|}
\hline Result & Score & Reaction \\
\hline \multirow{3}{*}{ Negative } & 1 & Absent \\
\cline { 2 - 3 } & 2 & Light erythema \\
\cline { 2 - 3 } & 3 & Erythema \\
\hline \multirow{2}{*}{ Positive } & 4 & Erythema, edema, papules \\
\cline { 2 - 3 } & 5 & Erythema, edema, papules, vesicles \\
\hline
\end{tabular}

Table 2: Signs and symptoms of Nickel allergy

\begin{tabular}{|c|c|}
\hline Intra-oral & Extra-oral \\
\hline Stomatitis from mild to severe erythema & Generalized urticarial \\
\hline Papula peri-oral rash & Widespread eczema \\
\hline Loss of metallic taste & Flare - up of allergic dermatitis \\
\hline Numbness & Exacerbation of pre-existing eczema \\
\hline Burning sensation & \\
\hline Soreness at the side of the tongue & \\
\hline Angular cheilitis & \\
\hline Severe gingivitis in the absence of plaque & \\
\hline
\end{tabular}

Table 3: Nickel-free and nickel-'lite' wires and brackets

\begin{tabular}{|c|c|c|}
\hline \multirow{2}{*}{ Company } & \multicolumn{2}{|c|}{ Nickel-free products } \\
\hline & Wires & Brackets \\
\hline $\begin{array}{c}\text { RMO Europe t } \\
\text { www.rmortho.com }\end{array}$ & Bendalloy TMA wire & Ceramic: Signature 3, Luxi 2 with gold slot \\
\hline $\begin{array}{l}\text { The Orthodontic Company } \\
\text { www.tocdental.com }\end{array}$ & $\begin{array}{l}\text { Resolve TMA wire } \\
\text { Bioforce wire with ionguard } \\
\text { Epoxy coated wires }\end{array}$ & $\begin{array}{l}\text { Ion-implanted stanless steel: Platina } \\
\text { Ceramic with glass slot: Mystique } \\
\text { Plastic: Oyster ligature free }\end{array}$ \\
\hline $\begin{array}{c}\text { 3M Unitek } \\
\text { www.3M.com/Unitek }\end{array}$ & Beta III Titanium & $\begin{array}{c}\text { Ceramic: Transcend, Clarity with stainless } \\
\text { steel slot } \\
24 \text { carat gold-plated brackets }\end{array}$ \\
\hline $\begin{array}{c}\text { Forestadent } \\
\text { www.forestadent.com }\end{array}$ & $\begin{array}{l}\text { TMA wire } \\
\text { Flat Line acrylic coated wire } \\
\text { Titanium coated archwire }\end{array}$ & $\begin{array}{l}\text { Ceramic with gold slot: Aspire } \\
\text { Plastic: Brilliant }\end{array}$ \\
\hline $\begin{array}{l}\text { American Orthodontics } \\
\text { www.americanortho.com }\end{array}$ & Beta Titanium wire & $\begin{array}{c}\text { White gold_60\% paladium: Virage } \\
\text { Polycarbonate } 20 / 40 \\
\text { Reinforced polycarbonate: Silkon } \\
\text { Urethane: Classic } \\
\end{array}$ \\
\hline $\begin{array}{l}\text { TP Orthodontics } \\
\text { www.tportho.com }\end{array}$ & Timmolium (TMA) & $\begin{array}{l}\text { Nickel 'free’ stainless steel: Avid } \\
\text { Ceramic: MXI } \\
\text { Cobalt chrome: Nu edge }\end{array}$ \\
\hline $\begin{array}{l}\text { Ormco/A Company } \\
\text { www.ormco.com }\end{array}$ & TMA & $\begin{array}{l}\text { Ceramic: Inspire } \\
\text { Gold: Ortho } 2\end{array}$ \\
\hline
\end{tabular}




\begin{tabular}{|c|c|c|}
\hline & & Titanium brackets \\
\hline $\begin{array}{c}\text { The Dental Directory } \\
\text { www.dental-directory.co.uk }\end{array}$ & Betaforce beta titanium & Composite with metal slot: Avalon \\
\hline HSR Primo www.hsrprimo.co.uk & Biosteel (0.2\% Ni) & Siliaceous copolymer-Natura \\
\hline Ortho-care www.orthocare.co.uk & Gold-plated wires Beta titanium wire & $\begin{array}{c}\text { Polycarbonate: Polar, Polar plus with gold slot } \\
\text { Ceramic: Desire with gold slot }\end{array}$ \\
\hline $\begin{array}{c}\text { Precision Orthodontics } \\
\text { www.orthoorganizer.co.uk }\end{array}$ & $\begin{array}{c}\text { Nickel-lite: Cobalt chromium alloy } \\
\text { CNA beta titanium Gold-plated wires } \\
\text { Resin coated wires }\end{array}$ & $\begin{array}{c}\text { Composite with gold slot: Envision } \\
\text { Nickel-lite: Cobalt chromium alloy } \\
\text { Gold-plated brackets }\end{array}$ \\
\hline
\end{tabular}

Table 4: Other nickel-free and nickel-'lite' products

\begin{tabular}{|c|c|}
\hline Company & Other products \\
\hline TP Orthodontics www.tporto.com & Plastic-coated headgear \\
\hline Masel www.maselortho.com & TMA expansion screw \\
\hline Sheffield Orthodontic www.orthounlimited.com & Nickel-'free' ss wire for removeable appliances \\
\hline The Orthodontic Company www.tocdental.com & Glass fibre buccal tubes Epoxy-coated quick-tie ligs \\
\hline Ormco/A Company www.ormco & Titanium buccal tubes \\
\hline
\end{tabular}

\section{Latex Allergy}

Exposure to natural rubber latex (NRL) in the clinical environment has increased significantly since the mid- 1980s. Natural rubber (Latex) is a milky juice obtained from rubber tree, Hevea Brasiliensis. There has been increase in allergic reactions to natural rubber latex (NRL) over the past two decades due to increased in the use of latex based gloves as universal precaution measures. Jacobsen and Hensten Pettersen found that, from 1998 to 2000 , there had been a tenfold increase in reported reactions to NRL during orthodontic treatment ${ }^{[3]}$. Natural rubber latex is found in gloves, intraand extra-oral elastics, separators, elastomeric modules, elastomeric power chain, polishing rubber cups, band removers. The allergic compounds from natural latex include chemical substances associated to vulcanization, such as residual proteins and chemical substances from powder or talc. With latex both type I and type IV hypersensitivity reactions can occur. The prevalence of potential type I hypersensitivity to latex is lower than $1 \%$ in the general population and between 6-12\% among dental professionals [19]. Immediate (Type I) IgE Antibody mediated response to NRL usually occurs within 5-60 minutes of contact with allergen. Severe systemic reactions, involving the skin, airways and/ or cardiovascular systems, have been reported after cutaneous and respiratory exposure ${ }^{[20]}$. More than 10 deaths have been attributed to latex anaphylaxis ${ }^{[21]}$. Contact dermatitis is a T cell mediated, delayed hypersensitivity (Type IV) reaction. The allergens usually responsible for triggering the allergic reaction are the chemical accelerators like thiurams, carbamates and benzothiazoles that are used in the glove-manufacturing process ${ }^{[20]}$. Allergic contact dermatitis can result in an eczematous rash that is typically pruritic. If the mucosa is involved, it may swell, become erythematous or develop small vesicles. patient may also complain of a burning or itching sensation in the affected area ${ }^{[22]}$. The prevalence of NRL allergy has been reported as being less than $1 \%$ in the general population, $5-15 \%$ in $\mathrm{HCWs}$ and 24 $60 \%$ in patients with spina bifida ${ }^{[23]}$. Definitive diagnosis should be based on the medical history, and a positive skin reaction to specific chemicals present in natural rubber latex. A standard medical history should identify patients with confirmed NRL allergy. However, additional information pertinent to NRL allergy should be sought to help identify other patients at potentially increased risk of developing NRL allergy. Hypersensitivity to certain foods such as avocados, potatoes, bananas,

tomatoes, chestnuts, kiwi fruit and papaya is associated with NRL allergy ${ }^{[24]}$. A history of 'asthma-like' symptoms and previous adverse reactions following possible exposure to NRL-containing products also requires further investigation. Confirmation of latex allergy should be obtained by doing latex epicutaneous skin test using natural latex, to determine the presence of circulating antibodies to latex. It seems prudent that when treating patients with clinical and immunological evidence of NRL allergy, contact with potential allergens should be avoided. Patient should be managed in a 'latex-screened' environment and should be monitor every appointment for any signs of adverse reactions. There are a number of latex free alternatives to commonly used orthodontic materials (Table 5). In the latex sensitive patient, steel ligatures or self-ligating brackets may be preferred. Elastomeric separators can be replaced with selflocking separating springs ${ }^{[25]}$. Synthetic non-latex gloves made from nitrile, polychloroprene, elastyren and vinyl, are readily available for clinical use. NRL-free elastics are available but they showed greater hysteresis than NRL elastics i.e. $40 \%$ force decay as opposed to $25 \%$ over 24 hours [26]. Although NRL-free elastics do not perform as well as NRL elastics in laboratory

studies, it is unlikely that the relatively small mechanical differences in force decay would have a clinically significant effect.

Table 5: Examples of NRL-free products for use in orthodontics.

\begin{tabular}{|c|c|}
\hline Intra-oral & $\begin{array}{lr}\text { Extra-oral } \\
\end{array}$ \\
\hline Inter-arch elastics & $\begin{array}{c}\text { GAC (www.gacintl.com): NRL-Free Elastics; Leone (www.leone.it); Dentaurum (info@ dentaurum. de): } \\
\text { intra-oral elastics }\end{array}$ \\
\hline Intra-arch elastics & $\begin{array}{c}\text { 3M Unitek (3M.com): Alastic range of power chain and modules; Dentaurum Dentalastics: plastic } \\
\text { ligatures, ligature chain, rotation wedges, 'Personal’ coloured modules, Elasto-Force plastic chain; TP } \\
\text { Orthodontics (tportho@ @tportho.com): ligatures, e-links, e-chain }\end{array}$ \\
\hline Headgear & $\begin{array}{c}\text { TP Orthodontics: headgear components; } 3 \mathrm{M} \text { Unitek: headgear components, except lining in chin cup } \\
\text { which does contain NRL }\end{array}$ \\
\hline Separators & TP Orthodontics: self-locking separator springs, sep-a-rings; Dentaurum Dentalastics: separators \\
\hline
\end{tabular}




\begin{tabular}{|c|c|}
\hline Self-ligating brackets & Damon (www.ormco.com); Speed (www.speedsystem.com); Innovation (GAC); SmartClip (3M Unitek) \\
\hline Nickel titanium springs & GAC; Leone; 3M Unitek; Dentaurum \\
\hline Band remover & 3M Unitek; TP Orthodontics \\
\hline Polishing brush/cup & Contra petite Web disposable (www.youngdental.com) \\
\hline Gloves & $\begin{array}{c}\text { Kimberly-Clark (www.kchealthcare.com): Safeskin Purple Nitrile; Bodyguards Nitrile Gloves } \\
\text { (www.medisavers.co.uk); Schottlander (www.schottlander.co.uk): NRL-Free Nitrile; Regent } \\
\text { (www.regentmedical.com): Biogel Skinsense PI }\end{array}$ \\
\hline Masks without NRL ties & Kimberly-Clark: Technocol Soft, Technocol Fluidshield \\
\hline
\end{tabular}

This table is not exhaustive, and manufacturing processes may change. It is prudent to check with the manufacturer that their products are NRL free.

\section{Acrylic resin allergy}

Acrylic resins are widely used in dentistry, especially in orthodontics and prosthodontics. Increasing concerns about the biocompatibility of this material were evident a decade ago, when reactions were described in the literature ${ }^{[27-29]}$. Acrylic resins based on methylmethacrylate can produce type IV hypersensitivity reactions, which happen after re-exposing a subject to the allergen. Nealey and Del Rio ${ }^{[27]}$ described stomatitis venenata, a contact allergy caused by a prosthesis constructed of self-curing acrylic resin. McCabe and Basker ${ }^{[28]}$ reported 2 cases of sensitivity to acrylic and linked these reactions to the levels of residual monomer $(0.233 \%$ and $0.186 \%$, analyzed by gas chromatography). Likewise, allergic reaction to methylmethacrylate was shown by Giunta and Zablotsky, ${ }^{[29]}$ confirmed by patch testing and histopathologic evaluations. Many authors agree that residual monomer leaching into the oral environment is a main cause of allergic reactions. The residual monomer contents are usually about $1.5 \%$ to $4.5 \%$ in self-curing acrylic resins and about $0.3 \%$ in heat-curing resins ${ }^{[30]}$. Generally, allergic reactions to acrylic are local manifestations, but there are different clinical presentations like labial edema, ${ }^{[31]}$ erythema delineating the contact area, Burning sensations and chronic urticaria ${ }^{[32]}$. Although it is widely used, the orthodontic literature contains little information about allergic reactions to this material. Tatiana Siqueira Gonçalves et al in 2006 reported a case of allergy cause by a removable retainer constructed of clear self-curing methyl methacrylate acrylic resin. Continued use of acrylic appliance even after seeing the initial intraoral manifestation may also lead to gum hypertrophy in the adjoining area Although reactions to this kind of allergen are rare, ${ }^{33}$ awareness of local and systemic manifestations is important in orthodontic practice when a patient's general health is concerned. Owing to the frequent contact with, methacrlate resin Dental Health Care Workers are at increased risk of developing allergy. Kerosvo et al in 2000 conducted a survey on occupational problem among Finnish population in relation to orthodontics. They concluded that methacrylate and latex gloves were the two most commonly reported cause of hypersensitivity among clinician's. The adverse effects of acrylics were attributed both to the monomer during handling process of the material and to the acrylic dust generated during grinding of acrylic appiliance ${ }^{[34]}$. Suspicious changes should be investigated by a dermatologist and, whenever possible, confirmed by patch test. Overcoming allergic reactions in denture patients sensitized by methylmethacrylate might require, according to Kanerva et al, ${ }^{[35]} 1$ of 6 possibilities: cover the prosthesis with light polymerized methyl methacrylate, cover it with ultraviolet polymerized urethane acrylate, cover it with ultraviolet polymerized methacrylate, use a polycarbonate prosthesis, use vulcanite, or use titan associated to ceramic teeth. A patient allergic to methylmethacrylate was shown to also have positive patch test results to polysulfone and polycarbonate, leaving urethane dimethacrylate as the only choice ${ }^{[36]}$. Instead of methacrylate resin Clear aligner can be used as a retainer to avoid the allergic reactions. A bonded lingual retainer can be used instead of acrylic based removable retainer.

\section{Other metal allergy}

Chromium is the second most frequent metal to cause contact dermatitis [37]. Luciane et al in 2004 in their study demonstrated high sensitivity rates to chromium, in orthodontic patients $(21.1 \%)$, though greater tendency to positivity was found in male patients as compare to female. ${ }^{38}$ The chances of an adverse reaction to chromium found in dental materials, appears to be rare ${ }^{[39]}$. Similarly documented cases of platinum hypersensitivity are even rarer than chromium allergy. ${ }^{40}$ Resin composite materials could be an etiologic factor in the development of lichenoid reactions in the oral mucosa. ${ }^{41}$ The pathogenic mechanism may be related to contact allergy to formaldehyde formed in resin composite restorations. Though the chances of an adverse reaction to these dental materials, appears to be remote clinicians should nevertheless always be on the alert.

\section{Conclusion}

Safe and effective practice depends on identifying patients with allergy along with knowledge of materials that can potentially cause them. Diagnosis and treatment should include a multidisciplinary team. It is imperative for a practitioner to not only know the physical and mechanical properties of the materials being used, but also of the biologic compatibility of the material. Knowledge of alternatives to allergy-causing materials is also of prime importance in efficient management of patients in routine clinical practice. The clinician should be mindful of these reactions during the course of orthodontic treatment, and should know to diagnose and subsequent action to be taken in treatment plan. In all instances, the patient's well-being should guide treatment decisions, and general health-not just oral health-should be the goal.

\section{References}

1. Agaoglu G, Arun T, Izgü B, Yarat A. Nickel and chromium levels in the saliva and serum of patients with fixed orthodontic appliances. Angle Orthod 2001;71:37579.

2. Al-Tawil N, Marcusson J, Moller E. Lymphocyte transformation test in patients with nickel sensitivity: an aid to diagnosis. Acta Derm Venereol 1981;61:511-515.

3. Hensten-Pettersen A, Jacobsen N. Disintegration of orthodontic appliances in vivo. In: Eliades G, Eliades T, Brantley WA, Watts DC, editors. In vivo Aging of Dental Biomaterials. Chicago: Quintessence. 2003, 290-296.

4. Lowey MN. Allergic contact dermatitis associated with the use of Interlandi headgear in a patient with a history of atopy. Br Dent J. 1993;17:67-72.

5. Nielson NH, Menne T. Allergic contact sensitization in an unselected Danish population: the Glostrup allergy 
study, Denmark. Acta Derm Venereol 1992;72:456-460.

6. Van Loon LA, Van Elsas PW, Bos JD, Ten HarkelHagenaar HC, Krieg SR, Davidson CL. T-lymphocyte and Langerhans cell distribution in normal and allergically-induced oral mucosa in contact with nickelcontaining dental alloys. J Oral Pathol. 1988;17:129-137.

7. Barrett RD, Bishara SE, Quinn YK. Biodegradation of orthodontic appliances. Part 1: biodegradation of nickel and chromium in vitro. Am J Orthod Dentofac Orthop. 1993;103:8-14.

8. Bour H, Nicolas JF, Garrigue JL, Demidem A, Schmitt D. Establishment of nickel-specific $\mathrm{T}$ cell lines from patients with allergic contact dermatitis: Comparison of three different protocols. Clin Immunol Immunopathol. 1994;73:142-5.

9. Thyssen JP, Linneberg A, Menne T, Johansen JD. The epidemiology of contact allergy in the general population-prevalence and main findings. Contact Dermatitis. 2007;57:287-99.

10. Mortz CG, Lauritsen JM, Bindslev-Jensen C, Andeersen KE. Nickel sensitization in adolescents and association with ear piercing, use of dental braces and hand eczema. Acta Derm Venereol Suppl (Stockh). 2002;82:359-364.

11. Staerkjaer L, Menne T. Nickel allergy and orthodontic treatment. Eur J Orthod. 1990;12:284-289.

12. Bishara SE, Barrett RD, Selim MI. Biodegradation of orthodontic appliances. Part II. Changes in the blood level of nickel. Am J Orthod Dentofacial Orthop. 1993;103:115-119.

13. Genelhu MC, Marigo M, Alves-Oliveira LF, Malaquias LC, Gomez RS. Characterisation of nickel induced allergic contact stomatitis associated with fixed orthodontic appliances. Am J Orthod Dentofacial Orthop. 2005; 128:378-81.

14. Schultz JC, Connelly E, Glesne L, Warshaw EM. Cutaneous and oral eruption from oral exposure to nickel in dental braces. Dermatitis. 2004;15:154-157.

15. Menne T, Brandup F, Thestrup-Pedersen K, Veien NK et al. Patch test reactivity to nickel alloys. Contact Dermatitis. 1987;16:255-259.

16. Kim H, Johnson J. Corrosion of stainless steel, nickeltitanium, coated nickel-titanium and titanium orthodontic wire. Angel Orthod. 1999;69:39-44.

17. Toms AP. The corrosion of orthodontic wire. Eur J orthod. 1988;10:87-97.

18. Rahilly G, Price N. Current Products and Practice Nickel allergy and orthodontics Journal of Orthodontics. 2003;30:171-174.

19. Patel A, Burden DJ, Sandler J. Medical disorders and orthodontics Journal of Orthodontics. 2009;36:1-21.

20. Hain MA, Longman LP, Field EA, Harrison JE. Natural rubber latex allergy: implications for the orthodontist Journal of Orthodontics. 2007;34:6-11.

21. Gelfand DW. Am J Roentgenol. Barium enemas, latex balloons, and anaphylacticreactions. 1991;156(1):1-2.

22. Neiburger EJ. A case of possible latex allergy. J Clin Orthod. 1991;25:559-60.

23. Poley GE Jr, Slater JE. Latex allergy. J Allergy Clin Immunol. 2000;105:1054-62.

24. Cullinan P, Brown R, Field A, et al. Latex allergy. A position paper of the British Society of Allergy and Clinical Immunology. Clin Exp Allergy 2003;33:148499.

25. Hain MA, Longman LP, Field E, Harrison J. Natural rubber latex allergy: implications for the orthodontist. J
Orthod. 2007;34:6-11.

26. Russell KA, Milne AD, Khanna RA, Lee JM. In vitro assessment of the mechanical properties of latex and non latex orthodontic elastics. Am J Orthod Dentofacial Orthop. 2004;126:65-70.

27. Nealey ET, Del Rio CE. Stomatitis venenata: reaction of a patient to acrylic resin. J Prosthet Dent. 1969;21:480-4.

28. McCabe JF, Basker RM. Tissue sensitivity to acrylic resin: a method of measuring the residual monomer content and its clinical application. $\mathrm{Br}$ Dent $\mathrm{J}$ 1976;140:347-50.

29. Giunta J, Zablotsky N. Allergic stomatitis caused by selfpolymerizing resin. Oral Surg Oral Med Oral Pathol. 1976;41:631-7.

30. Hugget R, Brooks B, Bates JF. The effect of different curing cycles on levels of residual monomer in acrylic resin denture base materials. Quintessence Dent Technol 1984;8:365-70. 31.Ruiz-Genao DP, Moreno De Vega MJ, Sanchez Perez J, Garcia- Diez A. Labial edema due to an acrylic dental prosthesis. Contact Dermatitis. 2003;48:273-4.

31. Lunder T, Rogl-Butina M. Chronic urticaria from an acrylic dental prosthesis. Contact Dermatitis 2000;43:232-3.

32. Kanerva L, Rantanen T, Aalto-Korte K, Estlander T, Hannuksela M, Harvima RJ, et al. A multicenter study of patch test reactions with dental screening series. Am J Contact Dermat. 2001;12:83-7

33. Kerosuo H, Kerosuo L Kanerva. occupation-related health complaints among general dental dental practitioners, orthodontists, and office employees. Acta Odontol scand. 2000;58:207-212.

34. Kanerva L, Tarvainen K, Jolanki R, Estlander $\mathrm{T}$. Successful coating of an allergenic acrylate-based dental prosthesis. Am J Contact Dermat. 1995;6:24-7.

35. Tanoue M, Nagano K, Matsumura H. Use of a lightpolymerized Composite removable partial denture base for a patient Hypersensitive to poly (methylmethacrylate), polysulfone and Polycarbonate: a clinical report. J Prosthet Dent. 2005;93:17-20.

36. Park HY, Shearer TR. In vitro release of nickel and chromium from simulated orthodontic appliances. Am J Orthod Dentofacial Orthop. 1983;84:156-9.

37. Luciane M Menezes, Luis C Campos, Catia C Quinta, Ana M. Bolognese Hypersensitivity to metals in orthodontics Am J Orthod Dentofacial Orthop 2004;126:58-64.

38. Burrows D. Hypetsensitivity to mercury, nickel and chromium in relation to dental materials. Int Dent J. 1986;36:30-34.

39. William A Wiltshire, Maryna R Ferreira, At J Ligthelm. Allergies to dental materials (Quintessence Int. 1996;27:513-520.

40. Lind PO. Oral lichenoid reactions retalcd to composite reslorations. Preliminary report. Acta Odontol. Scatid. 1988;46:63-65. 